\title{
Numerical analysis of electro-osmosis consolidation: a case study
}

\author{
J. YUAN* and M. A. HICKS*
}

\begin{abstract}
A numerical model for the design and analysis of electro-osmosis consolidation in soft clay is used to study a well-documented full-scale field test. The large-strain model, which considers coupled electro-osmosis flow, hydraulic flow and electric density flow in a deformable elasto-plastic porous medium, is briefly introduced first. It is then used to analyse the field test, including a sensitivity analysis to study the uncertainty of the model in simulating the test. The results of the numerical analyses are found to be consistent with measurements of the ground settlement profile. Moreover, the sensitivity results illustrate that the soil improvement induced by electro-osmosis consolidation is sensitive to the electro-osmosis conductivity, and that consideration of the voltage drop that occurs at the electrodes during the test is necessary.
\end{abstract}

KEYWORDS: electrokinetics; finite-element modelling; ground improvement; settlement

ICE Publishing: All rights reserved

\author{
NOTATION \\ b body force vector \\ $C_{\mathrm{p}}$ electrical capacitance per unit volume \\ $\mathbf{D}_{\mathrm{ep}}$ stress-strain matrix \\ $F^{\text {ext }}$ external loads vector \\ $f$ arbitrary scalar valued function \\ I identity vector \\ $\boldsymbol{j}$ electrical current flux \\ $\mathbf{K}_{\mathrm{c}}$ hydraulic flow matrix \\ $\mathbf{K}_{\text {eo }}$ electro-osmosis flow matrix \\ $\mathbf{K}_{\mathrm{nl}}$ non-linear stiffness matrix \\ $\mathbf{K}_{\sigma \mathrm{ce}} \quad$ current flux matrix \\ $K_{0} \quad$ coefficient of earth pressure at rest \\ $k_{\text {eo }}$ electro-osmosis permeability \\ $k_{\mathrm{w}}$ hydraulic conductivity \\ $k_{\text {бe }}$ electrical conductivity of the soil \\ L coupling matrix \\ $M$ friction constant \\ $p$ pore water pressure \\ $p$ pore water pressure vector \\ $\boldsymbol{Q}_{\mathrm{p}}^{\text {ext }} \quad$ external fluid supply vector \\ $Q_{\mathrm{V}}^{\text {ext }} \quad$ external current supply vector \\ $t$ time \\ $\boldsymbol{u}$ displacement vector \\ $V$ electric potential \\ $V$ electric potential vector \\ $v$ spatial velocity \\ $\bar{v}$ filtration velocity of water relative to soil skeleton \\ $\boldsymbol{X}$ reference configuration coordinates \\ $\boldsymbol{x}$ current configuration coordinates \\ $z$ elevation \\ $\gamma \quad$ unit weight of soil \\ $\gamma_{\mathrm{w}} \quad$ unit weight of water \\ $\varepsilon$ strain vector \\ $\kappa \quad$ unloading-reloading index \\ $\lambda$ plastic compression index \\ $v$ Poisson's ratio \\ $\pi \quad \pi$ th phase \\ $\sigma$ total Cauchy stress vector \\ $\sigma^{\prime}$ effective Cauchy stress vector
}

Manuscript received 31 March 2015; first decision 20 April 2015; accepted 11 June 2015.

Published online at www.geotechniqueletters.com on 17 August 2015.

*Section of Geo-Engineering, Faculty of Civil Engineering and Geosciences, Delft University of Technology, Delft, The Netherlands

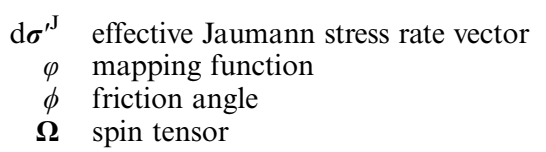

\section{INTRODUCTION}

As an innovative and effective ground improvement method for soft clays, electro-osmosis consolidation has generated much interest in geotechnical engineering for many decades. Since the 1960s, laboratory devices have been developed to measure electro-osmosis in clays (Gray, 1970; Lockhart \& Hart, 1988; Shang, 1997; Lefebvre \& Burnotte, 2002; Fourie et al., 2007; Gabrieli et al., 2008; Airoldi et al., 2009) although, due to their mechanical and hydraulic properties, clays are not easy to work with.

Since the pioneering work of Casagrande (1952), who investigated the strengthening of soft clay in slope stabilisation work by electro-osmosis consolidation, several successful field applications have been reported (Bjerrum et al., 1967; Chappell \& Burton, 1975; Lo \& Ho, 1991; Burnotte et al., 2004; Chew et al., 2004). For this purpose, feasibility studies and a proper design are important, although most field applications have been conducted based on laboratoryscale studies (e.g. Lefebvre \& Burnotte, 2002; Burnotte et al., 2004), which may be both time-consuming and costly. Hence numerical modelling is needed in the design and analysis of electro-osmosis consolidation in order to assess factors for achieving optimal dewatering effects and estimating the cost.

Esrig (1968) first proposed an analytical solution to calculate the excess pore water pressure in a one-dimensional uniform electric field. Based on Esrig's equations, many researchers have since presented analytical and numerical solutions for electro-osmosis consolidation (Lewis \& Garner, 1972; Wan \& Mitchell, 1976; Shang, 1998; Rittirong \& Shang, 2008; Tamagnini et al., 2010; Yuan et al., 2012, 2013, 2015; Jeyakanthan \& Gnanendran, 2013; Zhou et al., 2013; Hu \& Wu, 2014; Yuan \& Hicks, 2013, 2014, 2015).

Numerical simulations of full-scale field tests involving electro-osmosis consolidation are seldom reported because the available analytical and numerical models typically only consider simple geometries, boundary conditions and material behaviour. Recently, Rittirong \& Shang (2008) analysed the field test reported by Bjerrum et al. (1967) using a finitedifference model in which the settlement and undrained shear strength were considered indirectly. Yuan et al. (2013) analysed 
the electro-osmosis test carried out by Micic et al. (2003), accounting for the three-dimensional (3D) geometry and boundary conditions as well as elasto-plastic material behaviour. Hu \& Wu (2014) performed a numerical simulation of the field test conducted by Bjerrum et al. (1967); two-dimensional (2D) and 3D geometries were both accounted for, based on an elastic constitutive relationship and a single representative section between one anode and one cathode. The same field test was analysed by Yuan \& Hicks (2015), who considered large strain and elasto-plastic constitutive behaviour in a $2 \mathrm{D}$ simulation of a single representative section of the full test.

In this paper, a multi-dimensional numerical model (Yuan \& Hicks, 2015) is employed to analyse a well-documented large-scale field test of electro-osmosis consolidation (Burnotte et al., 2004). The model is able to simulate the complicated geometry and boundary conditions of the field test, including the presence of multiple electrodes, as well as practical features such as current intermittence. The model also considers geometric non-linearity and elasto-plastic soil mechanical behaviour, as well as allowing for the incorporation of non-linear variations of soil transport parameters (although this latter feature is not required or utilised in this case study). The model is briefly summarised and then the numerical results are compared with measured data from the field test.

\section{MATHEMATICAL MODELS}

\section{Large-strain analysis}

Following large-strain porous media theory, the kinematics and deformations of the solid skeleton are described using Lagrangian coordinates, while those of the pore water are described using Eulerian coordinates with respect to the current configuration of the solid skeleton, when the updated Lagrangian method is employed.

Consider an arbitrary reference configuration $\boldsymbol{X}$, which has position $\boldsymbol{x}$ at time $t$. The mapping function $\varphi$ relates the initial and current position vectors. Hence, for a typical timestep, the updated configuration of the body may be written as

$$
\boldsymbol{x}=\varphi(\boldsymbol{X}, t)
$$

The spatial velocity $\boldsymbol{v}$ of the material at point $\boldsymbol{x}$ is given by

$$
\boldsymbol{v}=\boldsymbol{v}(\boldsymbol{x}, t)=\frac{\partial \boldsymbol{x}}{\partial t}
$$

For an arbitrary scalar valued function $f(x, t)$, its material time derivative with respect to its spatial description, and referring to a moving particle of phase $\pi$, is defined by

$$
\frac{\mathrm{D}^{\pi} f^{\pi}}{\mathrm{D} t}=\frac{\partial f^{\pi}}{\partial t}+\nabla f^{\pi} \cdot \boldsymbol{v}^{\pi}
$$

In a multi-phase porous medium, it is common to assume the motion of the solid configuration as a reference and to describe the motion of the $\pi$ th phase particles relative to the solid (s). Hence the fluid relative velocity can be written as

$$
\boldsymbol{v}^{\pi \mathrm{s}}=\boldsymbol{v}^{\pi}-\boldsymbol{v}^{\mathrm{s}}
$$

By considering the above relative velocities, the material time derivative of $f^{\pi}$ with respect to the moving solid phase is given by

$$
\frac{\mathbf{D}^{\mathrm{s}} f^{\pi}}{\mathbf{D} t}=\frac{\mathbf{D}^{\pi} f^{\pi}}{\mathbf{D} t}+\nabla f^{\pi} \cdot \boldsymbol{v}^{\mathrm{s} \pi}
$$

\section{Governing equations}

In an updated Lagrangian formulation, the equilibrium equation at the current configuration is

$$
\nabla \cdot \boldsymbol{\sigma}+\boldsymbol{b}=0
$$

where $\boldsymbol{\sigma}$ is the total Cauchy stress vector and $\boldsymbol{b}$ is the body force vector. The principle of effective stress relates the total Cauchy stress to the effective Cauchy stress $\sigma^{\prime}$ through the pore water pressure $p$

$$
\boldsymbol{\sigma}=\boldsymbol{\sigma}^{\prime}+p \boldsymbol{I}
$$

where $\boldsymbol{I}$ is the identity vector. In a large-strain analysis, the effect of rigid body rotations must be considered in the stress-strain relations. This is often taken into account by using a frame-independent stress rate, such as the Jaumann stress rate, which is expressed as

$$
\mathrm{d} \boldsymbol{\sigma}^{\prime \mathrm{J}}=\mathrm{d} \boldsymbol{\sigma}^{\prime}-\mathrm{d} \boldsymbol{\Omega} \cdot \mathrm{d} \boldsymbol{\sigma}^{\prime}-\boldsymbol{\sigma}^{\prime} \cdot \mathrm{d} \boldsymbol{\Omega}^{\mathrm{T}}=\mathbf{D}_{\mathrm{ep}} \mathrm{d} \boldsymbol{\varepsilon}
$$

where $\boldsymbol{\Omega}$ is the spin tensor, $\mathbf{D}_{\mathrm{ep}}$ is the stress-strain matrix and $\varepsilon$ is the strain vector.

The water mass conservation equation can be written as

$$
\nabla \cdot\left(\boldsymbol{v}^{\mathrm{s}}+\overline{\boldsymbol{v}}\right)=0
$$

where $\boldsymbol{v}^{\mathrm{s}}$ is the velocity of the soil particles and $\overline{\boldsymbol{v}}$ is the filtration velocity of the water relative to the soil skeleton. According to Esrig's assumption (Esrig, 1968), the flow of fluid due to electrical and hydraulic gradients may be superimposed to obtain the total flow

$$
\overline{\mathbf{v}}=-\frac{k_{\mathrm{w}}}{\gamma_{\mathrm{w}}}\left(\nabla p+\gamma_{\mathrm{w}} z\right)-k_{\mathrm{eo}} \nabla V
$$

where $k_{\mathrm{w}}, \gamma_{\mathrm{w}}$ and $z$ are the hydraulic conductivity, the unit weight of water and the elevation, respectively, $k_{\mathrm{eo}}$ is the electro-osmosis permeability and $V$ is the electric potential.

By applying the conservation of charge and assuming that the current is steady state, the governing equation for the electric field can be represented by

$$
-\nabla \cdot \boldsymbol{j}=C_{\mathrm{p}} \frac{\partial V}{\partial t}
$$

in which $\boldsymbol{j}$ is the electrical current flux and $C_{\mathrm{p}}$ is the electrical capacitance per unit volume, which can be considered negligible for soil. According to Ohm's law, the electrical current flow can be expressed as

$$
\boldsymbol{j}=-k_{\text {бе }} \nabla V
$$

where $k_{\sigma \mathrm{e}}$ is the electrical conductivity of the soil.

\section{Finite-element formulation}

The matrix form of the coupled governing equations can be written as

$$
\left[\begin{array}{ccc}
\mathbf{K}_{\mathrm{nl}} & \mathbf{L} & 0 \\
\mathbf{L}^{\mathrm{T}} & 0 & 0 \\
0 & 0 & \mathbf{K}_{\mathrm{\sigma e}}
\end{array}\right]\left[\begin{array}{c}
\dot{\boldsymbol{u}} \\
\dot{\boldsymbol{p}} \\
\dot{\boldsymbol{V}}
\end{array}\right]+\left[\begin{array}{ccc}
0 & 0 & 0 \\
0 & \mathbf{K}_{\mathrm{c}} & \mathbf{K}_{\mathrm{eo}} \\
0 & 0 & 0
\end{array}\right]\left[\begin{array}{l}
\boldsymbol{u} \\
\boldsymbol{p} \\
\boldsymbol{V}
\end{array}\right]=\left[\begin{array}{l}
\dot{\boldsymbol{F}}^{\mathrm{ext}} \\
\boldsymbol{Q}_{\mathrm{p}}^{\mathrm{ext}} \\
\dot{\boldsymbol{Q}}_{\mathrm{V}}^{\mathrm{ext}}
\end{array}\right]
$$

Further details of the matrices and vectors are given elsewhere (Yuan \& Hicks, 2013, 2015). The global governing equations are solved using the classical finite-element method (Smith \& Griffiths, 2004). Yuan \& Hicks (2015) validated the formulation and demonstrated the performance of the various model components via a series of parametric studies.

\section{NUMERICAL ANALYSIS OF FIELD TEST}

A large-scale field test involving the electro-osmosis treatment of soft clay, as reported by Burnotte et al. (2004), was simulated using the finite-element model introduced in the previous section. The test site was located near 
Mont St-Hilaire, in the St Lawrence valley, about $40 \mathrm{~km}$ east of Montreal in Canada. The clay to be treated extended from an elevation of 33.0 to $25.5 \mathrm{~m}$. The test involved the installation of $5 \mathrm{~m}$ long electrodes arranged in six rows spaced $2 \mathrm{~m}$ apart, as shown in Fig. 1. In each row, the electrodes (two anodes and two cathodes) were positioned at spacings of $3 \mathrm{~m}$. The steel anodes were positioned between elevations of 31.5 and $26.5 \mathrm{~m}$ (Fig. 2), and linked to the ground surface by PVC tubes. Chemical treatment was introduced at the anodes to enhance the efficiency of the electro-osmosis consolidation. As reported by Burnotte et al. (2004), because of the chemical treatment, the measured electro-osmosis permeability and electrical conductivity were relatively constant until around day 34 . The cathodes were steel tubes of diameter $17 \mathrm{~cm}$, and extended from the ground surface to a depth of $14 \mathrm{~m}$.

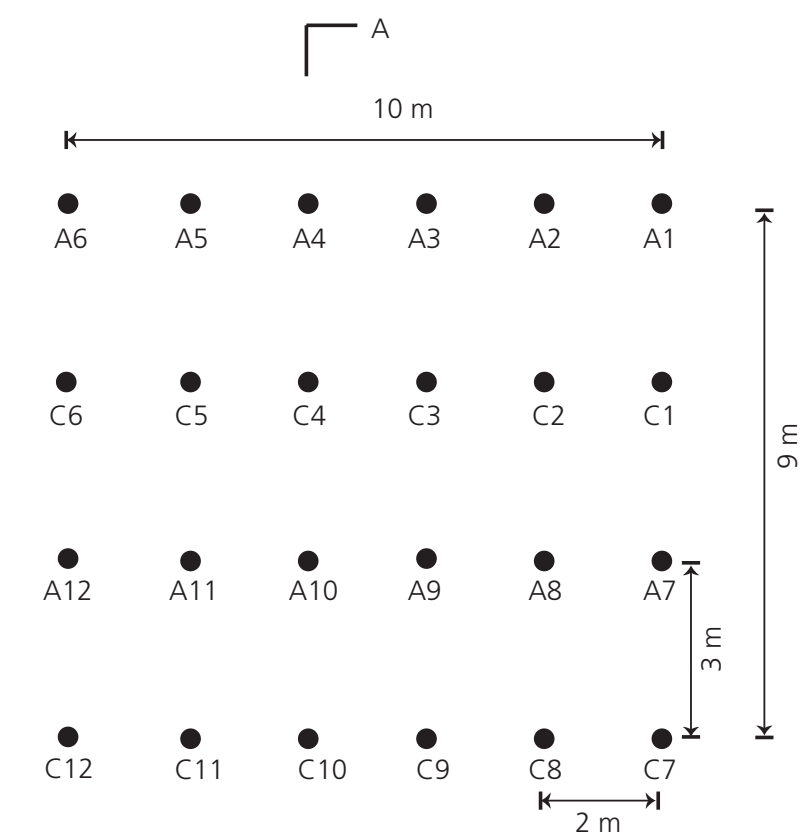

- Electrodes

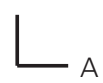

Fig. 1. Plan view of electrodes (after Burnotte et al. (2004))
The numerical analysis considered cross-section A (Fig. 1). Assuming that the influence of electro-osmosis consolidation is limited to within $20 \mathrm{~m}$ of the electrodes in the horizontal plane and down to $5 \mathrm{~m}$ below the treatment target clay layer, a rectangular geometry of $49 \times 20 \mathrm{~m}$ was selected for the analysis, as shown in Fig. 2. The finiteelement mesh was generated using eight-node quadrilateral elements for displacements, coupled to four-node quadrilateral elements for modelling excess pore water pressure and electrical potential. The profile was divided into four layers: layer 1 represents the berm and an underlying stiff clay layer; layer 2 represents a more impermeable clay layer; layer 3 represents the treatment target clay layer; and layer 4 represents a lower soil layer.

Figure 2 shows that movement in the horizontal direction is prevented at the left- and right-hand boundaries of the domain, and prevented in the vertical direction at the bottom boundary. Since water is allowed to flow out at the cathodes, the nodes lying along each cathode are free draining. The water table was at an elevation of $37.4 \mathrm{~m}$, so the water pressures are set to zero above the water table. An impervious layer was detected above the treated clay, isolating the anodes from free water in the embankment layer. Note that the slotted cathodes above the treatment zone are not considered in the numerical simulation because there was a stiff soil layer above the treatment zone and impervious layer. The voltage at each cathode was set to zero, whereas the voltage at each anode was the designated applied voltage. The bottom and two lateral boundaries were assumed to be impermeable to both water and electrical current.

The geotechnical properties of the soft clay, given in Table 1, were obtained directly from Burnotte et al. (2004), as were the electro-osmosis and hydraulic properties. Although the proposed model does allow for non-linear variation in transport parameters (Yuan \& Hicks, 2014, 2015), constant soil transport parameters seem the most appropriate choice in this case because of insufficient data to calibrate a non-linear relationship and because the evidence from the field test itself suggests that constant parameters are applicable in this instance.

The modified Cam clay model was used in the analysis and the parameters were obtained directly from the oedometric curve in Burnotte et al. (2004), except for the friction constant $M$. This was calculated from the relationship $M=$ $6 \sin \phi /(3-\sin \phi)$ and so, by assuming a friction angle $\phi$ of

Elevation

Electrodes

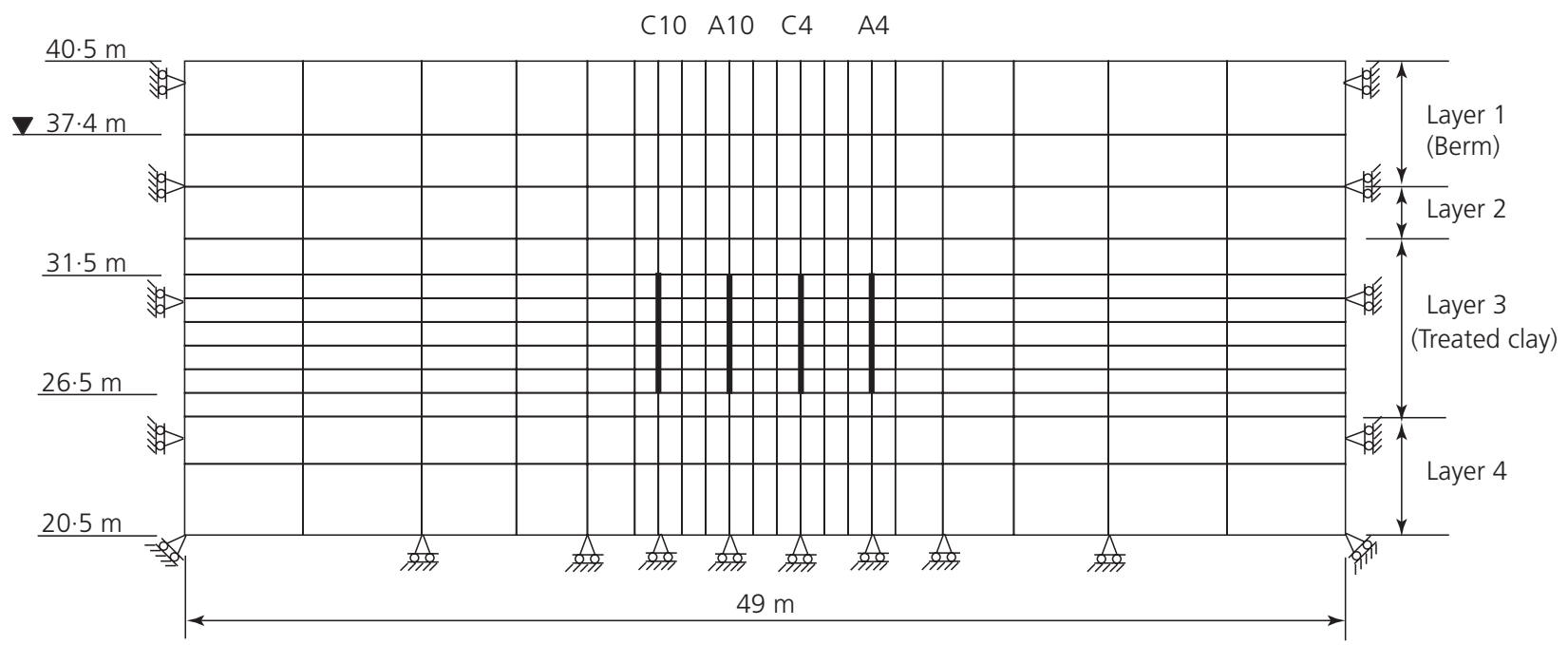

Fig. 2. Geometry and mesh of the model 
Table 1. Material parameters for the soft clay layer (after Burnotte et al. (2004))

\begin{tabular}{l|l}
\hline Parameter & Value \\
\hline$k_{\mathrm{w}}$ & $1.5 \times 10^{-9} \mathrm{~m} / \mathrm{s}$ \\
$k_{\mathrm{eo}}$ & $3.5 \times 10^{-9} \mathrm{~m}^{2} / \mathrm{V} . \mathrm{s}$ \\
$k_{\mathrm{\sigma e}}$ & $1 \cdot 0 \mathrm{~S} / \mathrm{m}$ \\
$\lambda$ & $0 \cdot 316$ \\
$\kappa$ & $0 \cdot 045$ \\
$M$ & 0.567 \\
$\nu$ & $0 \cdot 3$ \\
$K_{0}$ & 1.0 \\
$\gamma$ & $16.4 \mathrm{kN} / \mathrm{m}^{3}$ \\
\hline
\end{tabular}

$15^{\circ}, M=0 \cdot 567$. Poisson's ratio $v$ was assumed be $0 \cdot 3$ and the preconsolidation pressure under the berm was taken to be $120 \mathrm{kPa}$, as reported by Burnotte et al. (2004). The material parameters were assumed to be the same for all four layers, due to the deformation of the top two and the bottom layers being small and not affecting the final results significantly, except that a hydraulic conductivity of $1.5 \times 10^{-12} \mathrm{~m} / \mathrm{s}$ was assumed for layer 2 .

The applied voltage was varied during the field test, and current intermittence was also considered. The duration of the test was $48 \mathrm{~d}$, excluding those days during which the current was turned off. The applied voltage gradient between pairs of electrodes for the first $22 \mathrm{~d}$ was $0.33 \mathrm{~V} / \mathrm{m}$ on average; on day 22 it was reduced to $0.23 \mathrm{~V} / \mathrm{m}$ for one week and then restored to its initial value on day 29 . The voltage was intermittent for $3 \mathrm{~d}$ after $12 \mathrm{~d}$ of treatment, then for $7 \mathrm{~d}$ after the $22 \mathrm{nd}$ day of treatment, and lastly for $2 \mathrm{~d}$ after treatment day 34 .

To address the uncertainty in some of the model inputs, a sensitivity analysis was conducted for friction angle $\phi$, hydraulic conductivity $k_{\mathrm{w}}$, electro-osmosis permeability $k_{\mathrm{eo}}$ and the effects of an unplanned voltage drop at the anode during the last two weeks of treatment. As the friction angle of the clay was chosen to be $15^{\circ}$, the sensitivity analysis also considered values of $10^{\circ}$ and $20^{\circ}$. The hydraulic conductivity of the treated clay measured in odeometer tests was between $1 \times 10^{-9}$ and $2 \times 10^{-9} \mathrm{~m} / \mathrm{s}$, and so these upper and lower limits were also considered. Moreover, based on the field measurements, it appears to be reasonable to take a value of $3.5 \times 10^{-9}$ $\mathrm{m}^{2} /$ V.s for the electro-osmosis permeability for the main analysis, whereas values of $3.0 \times 10^{-9}$ and $4.0 \times 10^{-9} \mathrm{~m}^{2} / \mathrm{V}$.s were adopted for the sensitivity analyses. As observed in the field test, the treatment remained highly effective for the first $33 \mathrm{~d}$, but became much less effective in the last 2 weeks. Hence voltage drop factors of 0.5 and 0.7 were also considered, so that voltage gradients of $0 \cdot 165$ and $0.23 \mathrm{~V} / \mathrm{m}$ were applied after day 34 in the sensitivity analyses.

\section{RESULTS AND DISCUSSION}

Results of the case study

Figure 3 shows excellent agreement between the computed and measured average settlements, especially for the first $34 \mathrm{~d}$ of the treatment period. The computed settlements were larger than the measured values between days 34 and 48 because, as reported for the field test, electro-osmosis became much less effective in the last 2 weeks, but this was not considered in the simulation. As can be seen in Fig. 3, a very slight discontinuity in settlement occurred on days 12 , 22 and 34, due to a small rebound in settlement caused by the absence of an electric field during the periods of current intermittence. Note that the current intermittent periods are not included in the timescale of the simulation - that is, the time axis (for this and later figures) refers only to the treatment time.

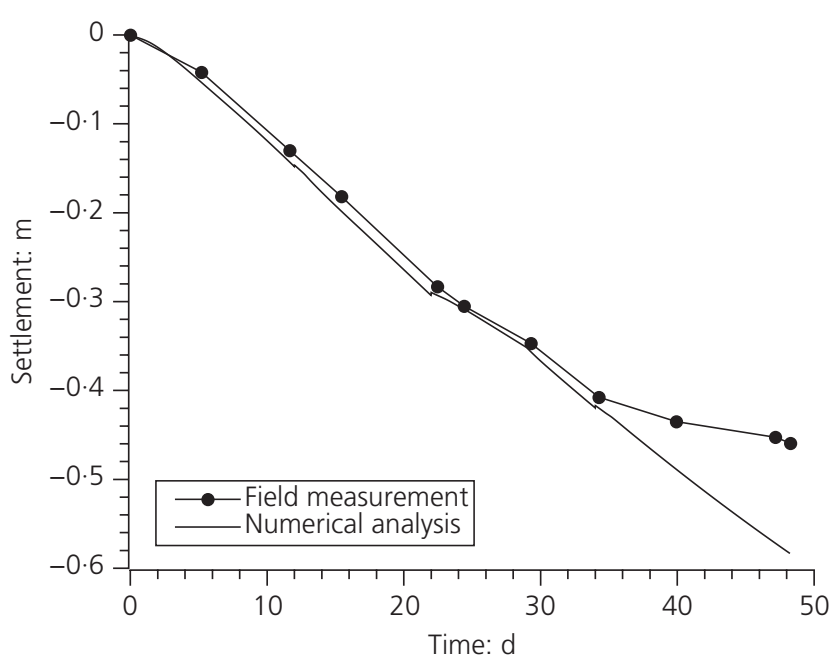

Fig. 3. Computed and measured average surface settlement versus time

The measured and computed settlement profiles at different times and the settlement contours after $48 \mathrm{~d}$ are illustrated in Figs 4 and 5, respectively. There is good agreement between the computed and measured surface profiles (Fig. 4), except on day 48 for the reasons discussed above. The effective area reported in the field test was only limited by the development of cracks, $5 \mathrm{~m}$ behind the outer row of anodes and $4 \mathrm{~m}$ behind the outer row of cathodes. Figure 6 shows close correlation between the computed horizontal surface displacement and the locations of the cracks observed in the field test; that is, the cracks are close to where the computed horizontal tensile strains are highest.

Due to the 2D assumption, the electrical field variations in the space between adjacent rows of electrodes (in the third dimension) were not considered. This means that the model predicts a stronger electrical current intensity than a 3D model, and this will result in an overestimation of the surface settlement. Therefore, 3D effects merit further investigation.

\section{Parametric study}

Figures 7-10 show the variation of settlement with time plots for various sensitivity analyses. As seen in Figs 7 and 8, the computed final settlement was relatively insensitive to the friction angle and hydraulic conductivity. In contrast,

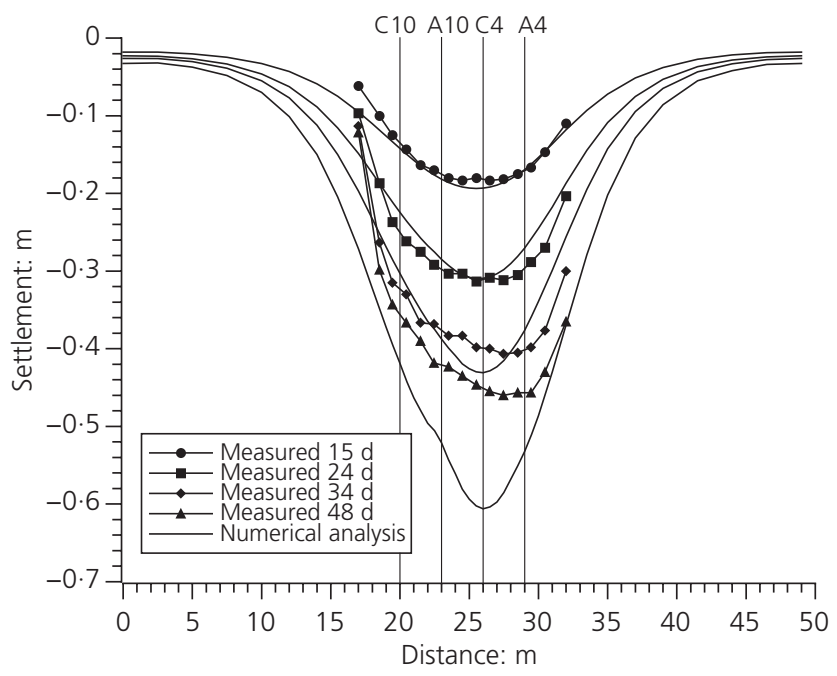

Fig. 4. Computed and measured surface settlement after 15, 24 , 34 and $48 \mathrm{~d}$ of treatment 


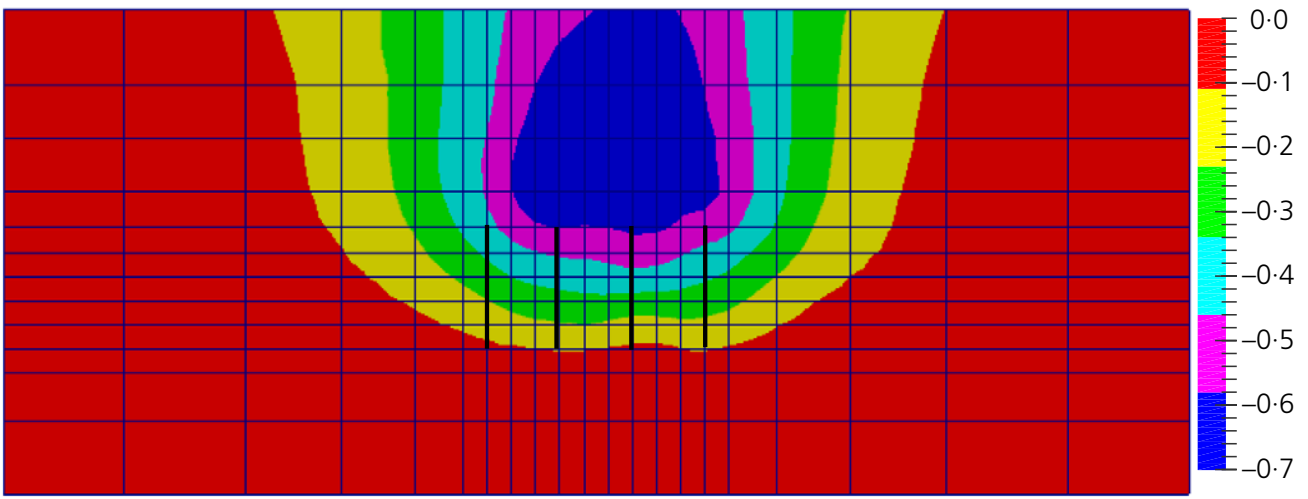

Fig. 5. Computed settlement contours (in $\mathrm{m}$ ) after $48 \mathrm{~d}$ of treatment

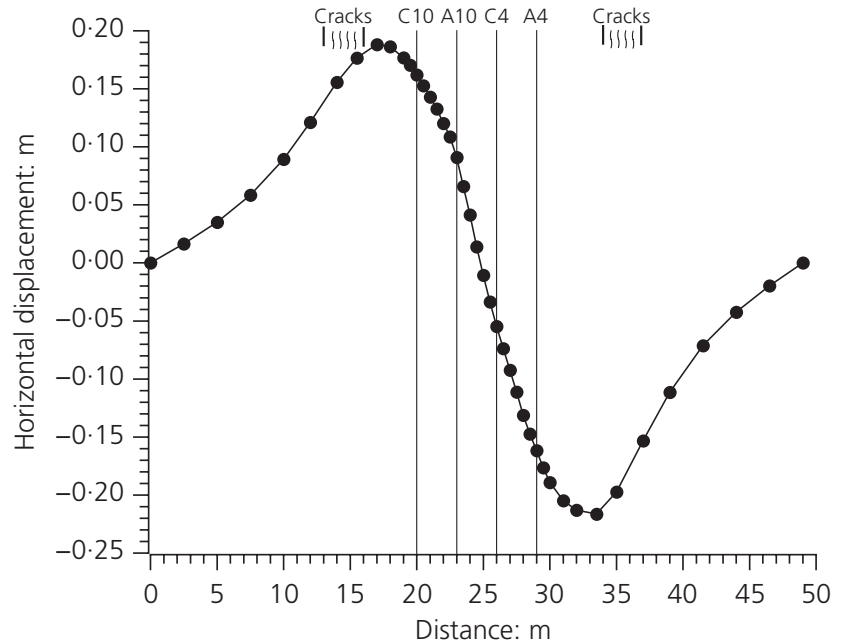

Fig. 6. Computed horizontal displacement along the surface after $48 \mathrm{~d}$ of treatment

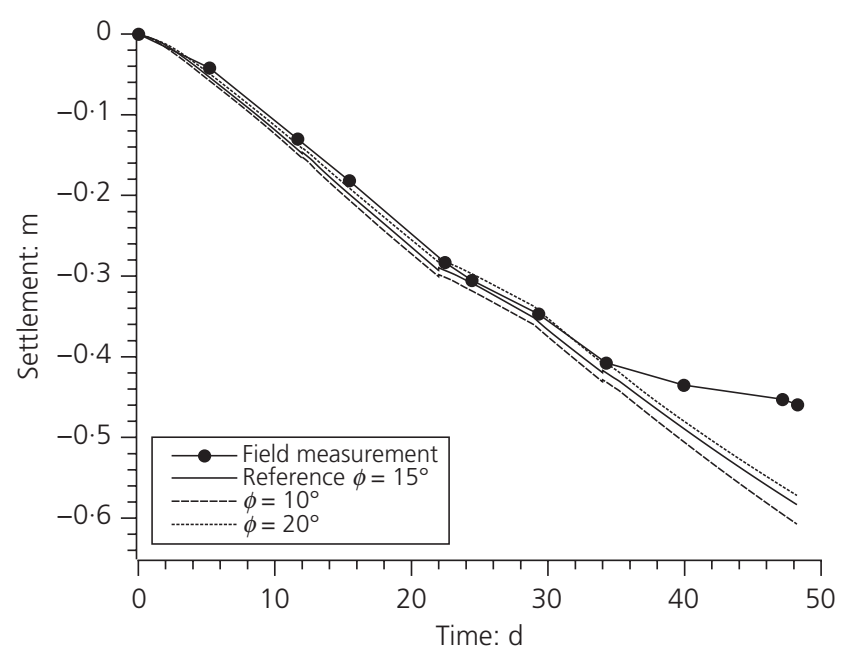

Fig. 7. Influence of friction angle on computed settlement

Fig. 9 shows the significant influence of the electro-osmosis permeability, with the computed settlements for $k_{\mathrm{eo}}=$ $3.0 \times 10^{-9}$ and $4.0 \times 10^{-9} \mathrm{~m}^{2} /$ V.s being around $13 \%$ lower and higher than the reference case, respectively.

The influence on the computed settlement of a decrease in the voltage at the anode after $34 \mathrm{~d}$ of treatment is shown in Fig. 10. In the reference analysis there was no voltage drop at the anode after day 34, but this is not supported by field observations and it overestimates the final ground settlement

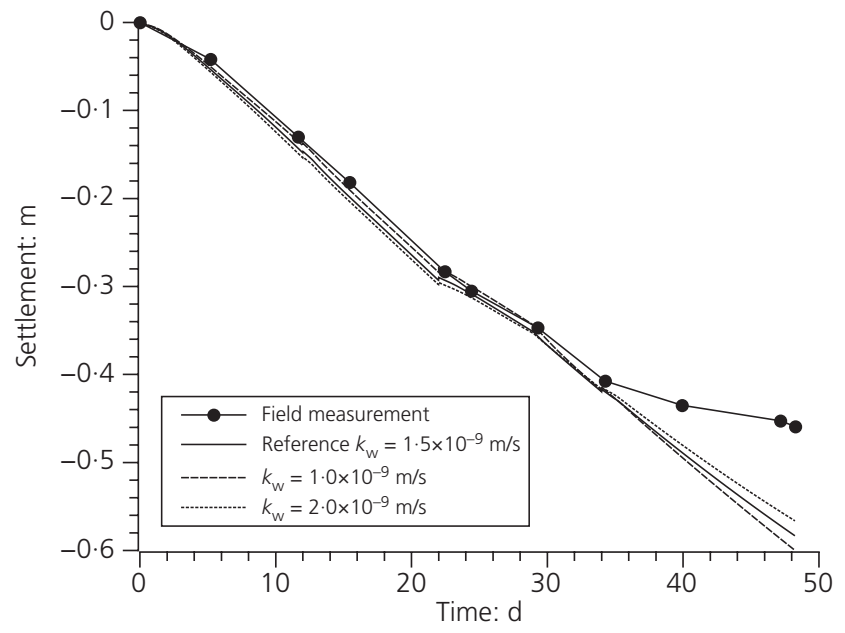

Fig. 8. Influence of hydraulic conductivity on computed settlement

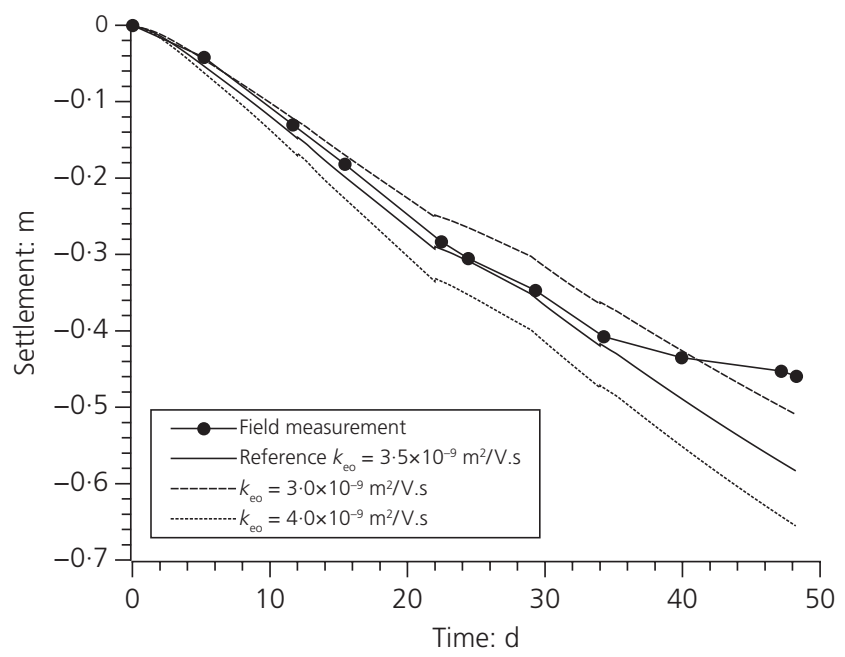

Fig. 9. Influence of electro-osmosis permeability on computed settlement

by $26 \cdot 9 \%$. In contrast, when voltage drop factors of $0 \cdot 5$ and $0 \cdot 7$ are incorporated in the analysis after day 34 , overestimation of the final settlement reduces to 4.7 and $13.2 \%$, respectively.

\section{CONCLUSIONS}

A numerical model for analysing the electro-osmosis treatment of soft clay has been briefly summarised. The model, 


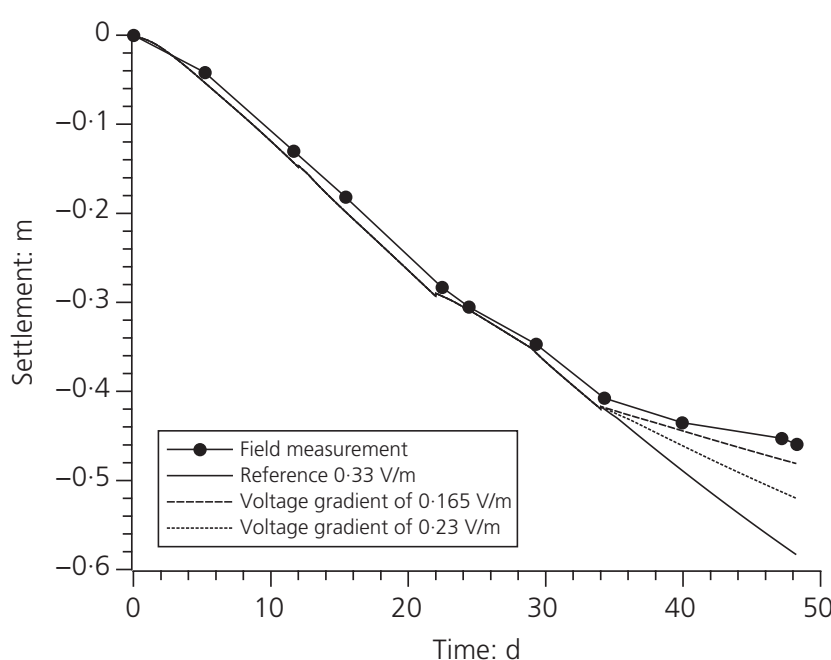

Fig. 10. Influence of drop in voltage gradient on computed settlement

which incorporates the modified Cam clay constitutive model, was used to simulate ground settlement due to electro-osmosis consolidation for a well-documented largescale field test. Overall, very good agreement between the computed and measured ground surface settlements was obtained, despite the deviation in surface settlement in the last 2 weeks due to voltage loss at the soil-electrode interface in the field test. The comparison demonstrates the capability of the proposed finite-element model in modelling field electro-osmosis treatment.

Furthermore, the results demonstrate that the analysis is sensitive to the electro-osmosis permeability, but not to the friction angle or hydraulic conductivity. The results of the parametric study show that, by incorporating the effects of voltage drop in the latter stage of the electro-osmosis treatment, the accuracy of the numerical analysis is improved. Overall, the results in this paper demonstrate that the numerical model has potential use in the design and analysis of electro-osmosis consolidation treatment for engineering applications.

\section{REFERENCES}

Airoldi, F., Jommi, C., Musso, G. \& Paglino, E. (2009). Influence of calcite on the electrokinetic treatment of a natural clay. J. Appl. Electrochem. 39, 2227-2237.

Bjerrum, L., Moum, J. \& Eide, O. (1967). Application of electro-osmosis to a foundation problem in a Norwegian quick clay. Géotechnique 17, No. 3, 214-235.

Burnotte, F., Lefebvre, G. \& Grondin, G. (2004). A case record of electroosmotic consolidation of soft clay with improved soil electrode contact. Can. Geotech. J. 41, No. 6, 1038-1053.

Casagrande, L. (1952). Electro-osmotic stabilization of soils. J. Boston Soc. Civ. Eng. 39, No. 1, 51-83.

Chappell, B. A. \& Burton, P. L. (1975). Electro-osmosis applied to unstable embankment. J. Geotech. Engng Div. ASCE 101, No. 8, 733-740.

Chew, S. H., Karunaratne, G. P., Kuma, V. M., Lim, L. H., Toh, M. L. \& Hee, A. M. (2004). A field trial for soft clay consolidation using electric vertical drains. Geotex. Geomem. 22, No. 1, 17-35.

Esrig, M. I. (1968). Pore pressures, consolidation and electrokinetics. J. Geotech. Engng Div. ASCE 94, No. 4, 899-921.

Fourie, A. B., Johns, D. G. \& Jones, C. J. (2007). Dewatering of mine tailings using electrokinetic geosynthetics. Can. Geotech. J. 44, No. 2, 160-172.

Gabrieli, L., Jommi, C., Musso, G. \& Romero, E. (2008). Influence of electroosmotic treatment on the hydro-mechanical behaviour of clayey silts: preliminary experimental results. J. Appl. Electrochem. 38, No. 7, 1043-1051.

Gray, D. H. (1970). Electrochemical hardening of clay soils. Géotechnique 20, No. 1, 81-93.

Hu, L. \& Wu, H. (2014). Mathematical model of electro-osmotic consolidation for soft ground improvements. Géotechnique 64, No. 2, 155-164.

Jeyakanthan, V. \& Gnanendran, C. (2013). Elastoplastic numerical approach for predicting the electro-osmotic consolidation behaviour of soft clays. Can. Geotech. J. 50, No. 12, 1219-1235.

Lefebvre, G. \& Burnotte, F. (2002). Improvements of electroosmotic consolidation of soft clays by minimizing power loss at electrodes. Can. Geotech. J. 39, No. 2, 399-408.

Lewis, R. W. \& Garner, R. W. (1972). A finite element solution of coupled electrokinetic and hydrodynamic flow in porous media. Int. J. Num. Methods Engng 5, No. 1, 41-55.

Lo, K. \& Ho, K. (1991). The effects of electroosmotic field treatment on the soil properties of a soft sensitive clay. Can. Geotech. J. 28, No. 6, 763-770.

Lockhart, N. C. \& Hart, G. H. (1988). Electro-osmotic dewatering of fine suspensions: the efficacy of current interruptions. Drying Technol. 6, No. 3, 415-423.

Micic, S., Shang, J. Q. \& Lo, K. (2003). Improvement of the load-carrying capacity of offshore skirted foundations by electrokinetics. Can. Geotech. J. 40, No. 5, 949-963.

Rittirong, A. \& Shang, J. Q. (2008). Numerical analysis for electro-osmotic consolidation in two dimensional electric field. Proc. 18th Int. Offshore and Polar Engineering Conf., Vancouver, 566-572.

Shang, J. Q. (1997). Zeta potential and electroosmotic permeability of clay soils. Can. Geotech. J. 34, No. 4, 627-631.

Shang, J. Q. (1998). Electroosmosis-enhanced preloading consolidation via vertical drains. Can. Geotech. J. 35, No. 3, 491-499.

Smith, I. M. \& Griffiths, D. V. (2004). Programming the finite element method, 4th edn., Chichester: Wiley.

Tamagnini, C., Jommi, C. \& Cattaneo, F. (2010). A model for coupled electro-hydro-mechanical processes in fine grained soils accounting for gas generation and transport. An. Acad. Brasil. Cienc. 82, No. 1, 169-193.

Wan, T. \& Mitchell, J. K. (1976). Electroosmotic consolidation of soils. J. Geotech. Engng Div. ASCE 101, No. 5, 503-507.

Yuan, J. \& Hicks, M. A. (2013). Large deformation elastic electroosmosis consolidation of clays. Comput. Geotech. 54, 60-68.

Yuan, J. \& Hicks, M. A. (2014). Numerical modelling of electro-osmosis consolidation of unsaturated clay at large strain. Proc. 8th Euro. Conf. on Numerical Methods in Geotechnical Engineering, NUMGE 2014, Delft, 2, 1061-1066.

Yuan, J. \& Hicks, M. A. (2015). Numerical simulation of elastoplastic electro-osmosis consolidation at large strain. Acta Geotech. in press.

Yuan, J., Hicks, M. A. \& Dijkstra, J. (2012). Multi-dimensional electro-osmosis consolidation of clays. Proc. Int. Symp. on Ground Improvement, Brussels, 2, 241-248.

Yuan, J., Hicks, M. A. \& Dijkstra, J. (2013). Numerical model of elasto-plastic electro-osmosis consolidation of clays. Proc. ASCE Poromechanics V, Vienna, 2076-2085.

Yuan, J., Hicks, M. A. \& Jommi, C. (2015). Large strain consolidation of clays: numerical comparison between evaporation and electro-osmosis dewatering. Proc. 14th Int. Conf. of International Association for Computer Methods and Recent Advances in Geomechanics, IACMAG 2014, Kyoto, 1655-1660.

Zhou, Y., Deng, A. \& Wang, C. (2013). Finite-difference model for one-dimensional electro-osmotic consolidation. Comput. Geotech. 54, 152-165.

\section{WHAT DO YOU THINK?}

To discuss this paper, please email up to 500 words to the editor at journals@ice.org.uk. Your contribution will be forwarded to the author(s) for a reply and, if considered appropriate by the editorial panel, will be published as a discussion. 